\title{
Model systemu sieć trakcyjna-pojazd do analizy zjawisk zachodzących podczas hamowania pojazdu
}

\begin{abstract}
W artykule opisano model systemu trakcji elektrycznej prądu stałego DC: - podstacja trakcyjna, sieć trakcyjna, pojazd hamujacy i pojazd pobierajacy energię. Model obwodu głównego pojazdu hamujacego zawiera: filtr wejściowy (czwórnik LC typu „gamma"), gataź hamowania elektrycznego sktadajaca sie z tranzystora $-T_{h}$ i rezystora hamowania $-R_{h}$, falownik napięcia -FN zasilajacy jeden silnik asynchroniczny -AC (zasilanie indywidualne). Obwód główny pojazdu pobierajacego energie zamodelowano $w$ postaci czwórnika $L C$ i rezystancji $R_{p 2}$ o zmiennej wartości na której wydziela się energia pobierana przez pojazd. Na podstawie modelu matematycznego opracowano model strukturalny oparty na procedurach $i$ oprogramowaniu narzędziowym MatlabSimulink. Pokazano przyktadowe wyniki symulacji modelu.
\end{abstract}

\section{Wstęp}

$\mathrm{Z}$ odzyskiem energii podczas hamowania pojazdu w trakcji elektrycznej wiąże się nadzieje na poprawę efektywności energetycznej sytemu. Towarzyszy temu jednak wiele niekorzystnych zjawisk. Powodowane rekuperacją energii wahania napięcia w sieci zależą od mocy hamowania, obciążenia aktualnego układu. Harmoniczne napięcia wnoszone przez przerywacz hamowania wywołują dodatkowe pulsacje prądu w sieci trakcyjnej oraz mogą być powodem złej pracy silników napędowych, zakłócać pracę urządzeń przytorowych. Do analizy oddziaływania pojazdu hamującego na prąd w sieci trakcyjnej przyjęto przykładowy system obejmujący: podstację trakcyjna prądu stałego, sieć trakcyjna, elektryczny pojazd trakcyjny (hamujaccy) oraz pojazd trakcyjny pobierający energię.

\section{Model matematyczny systemu}

Dla potrzeb analizy przyjęto jednostronny układ zasilania sieci trakcyjnej. Modelem zastępczym podstacji jest źródło napięcia $\left(\mathrm{E}_{\mathrm{p}}\right)$ i szeregowo połączona $\mathrm{z}$ nią rezystancja $\left(\mathrm{R}_{\mathrm{p}}\right)$ oraz indukcyjność $\left(\mathrm{L}_{\mathrm{p}}\right)$. W szereg włączono diodę idealną, która odwzorowuje prostownik w podstacji trakcyjnej. Sieć trakcyjna została zamodelowana parametrami $\mathrm{R}_{\mathrm{st}}(1), \mathrm{L}_{\mathrm{st}}(1)$ których wartość zależna jest długości sieci trakcyjnej. Obwody główne modelowanych pojazdów składają się z czterech równolegle połączonych układów. Model obwodu głównego pojazdu hamującego zawiera: filtr wejściowy (czwórnik LC typu „gamma”), gałąz hamowania elektrycznego składająca się $z$ tranzystora $-T_{h} i$ rezystora hamowania $-\mathrm{R}_{\mathrm{h}}$, falownik napięcia $-\mathrm{FN}$ zasilający jeden silnik asynchroniczny -AC (zasilanie indywidualne). Obwód główny pojazdu pobierajacego energię zamodelowano $\mathrm{w}$ postaci czwórnika LC $\mathrm{i}$ rezystancji $\mathrm{R}_{\mathrm{p} 2} \mathrm{O}$ zmiennej wartości na której wydziela się energia pobierana przez pojazd. Schemat funkcjonalny analizowanego systemu został przedstawiony na rys. 1 .

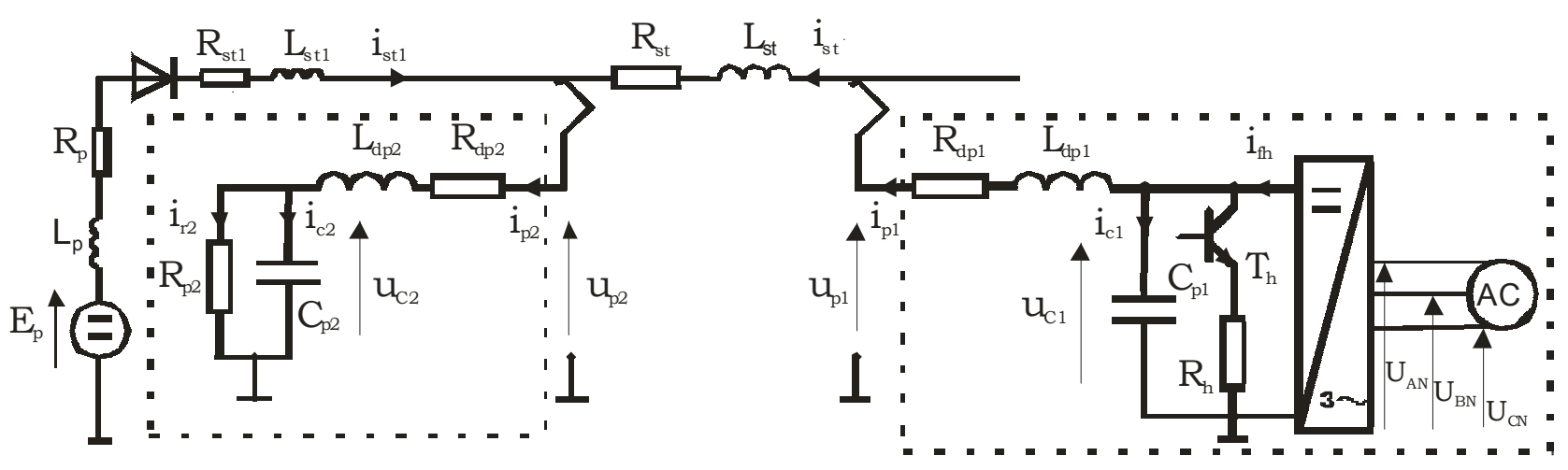

Rys. 1. Schemat funkcjonalny uproszczonego modelu systemu trakcyjnego 
Wykaz ważniejszych oznaczeń do rys.1:

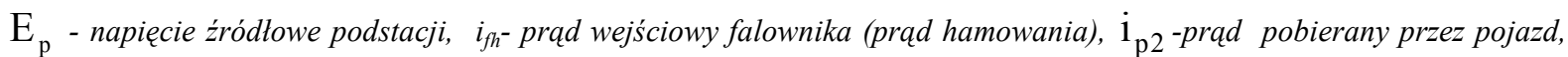

$\mathrm{i}_{\mathrm{st}}-$ prad $w$ sieci trakcyjnej, $\mathrm{u}_{\mathrm{c} 1}$ - napięcia na kondensatorze $C_{p 1}, \mathrm{u}_{\mathrm{c} 2}$ - napięcia na kondensatorze $C_{p 2}, \mathrm{u}_{\mathrm{p} 1}, \mathrm{u}_{\mathrm{p} 2}-$ odpowiednio napięcie na pantografie pojazdu hamujacego i pobierajacego energię, $L_{d p i}, R_{d p i}, C_{p i}$-odpowiednio indukcyjność, rezystancja, pojemność dławika filtru LC pojazdu $(i=1,2), \mathrm{L}_{\mathrm{st}}(1)$ - indukcyjność sieci trakcyjnej zależnej od dlugości odcinka, $\mathrm{L}_{\mathrm{p}}$ - indukcyjność zastępcza podstacji trakcyjnej, $\mathrm{R}_{\mathrm{p}}$ - rezystancja zastępcza podstacji trakcyjnej, $\mathrm{R}_{\mathrm{st}}(1)$ rezystancja sieci trakcyjnej zależnej od dlugości odcinka, $R_{p 2}$ - rezystancja pojazdu pobierajacego energię.

\subsection{Falownik napięcia}

Falownik napięcia jest urządzeniem energoelektronicznym, którego właściwości statyczne i dynamiczne zależą głównie od rodzaju sterowników i typu elementów energoelektronicznych (tyrystory GTO, tranzystory IGBT) tworzących łączniki (zawory) elektryczne. Wspólną cechą tych łączników jest wynikająca z ich nieliniowości charakterystyk zdolność do pracy w dwóch stanach: stanu przewodzenia, w którym nawet przy bardzo dużych prądach płynących przez łącznik, spadek napięcia na nim ograniczony jest do kilku woltów oraz stanu zaporowego, w którym nawet przy bardzo dużych napięciach na łączniku prąd płynący przez niego nie przekracza wartości wyrażających się w miliamperach. Przyjęto opis matematyczny elektrycznego łącznika jako bezstratnego przełącznika pomiędzy dwoma stanami: stanem bezstratnego przewodzenia i stanem zaporowym. Możliwe stany łączników w trzech gałęziach falownika reprezentowane są przy pomocy zmiennych $\mathrm{K}_{\mathrm{A}}, \mathrm{K}_{\mathrm{B}}$, $\mathrm{K}_{\mathrm{C}}$. Każda $\mathrm{z}$ tych trzech zmiennych może przyjmować wartość 1 albo 0 . Poprzez wybór odpowiedniej strategii załączania łączników mamy wpływ na właściwe kształtowanie przebiegów trójfazowych zapięć zasilających silnik zarówno co do amplitudy harmonicznej podstawowej jak i zawartości wyższych harmonicznych. Napięcia wyjściowe $U_{A N}(t), U_{B N}(t), U_{B N}(t)$ falownika jest wartością wynikającą $\mathrm{z} \mathrm{K}_{\mathrm{A}}, \mathrm{K}_{\mathrm{B}}, \mathrm{K}_{\mathrm{C}}$ oraz wartości napięcia na kondensatorze $\mathrm{C}_{\mathrm{p} 1}$, opisaną wyrażeniem:

$$
\left[\begin{array}{l}
U_{A N}(t) \\
U_{B N}(t) \\
U_{C N}(t)
\end{array}\right]=\left[\begin{array}{l}
K_{A} \\
K_{B} \\
K_{C}
\end{array}\right]\left[u_{c 1}(t)\right]
$$

Każdemu układowi łączników $\left(\mathrm{K}_{\mathrm{A}}, \mathrm{K}_{\mathrm{B}}, \mathrm{K}_{\mathrm{C}}\right)$ odpowiada ściśle określone położenie wektora przestrzennego napięcia stojana zasilającego silnik asynchroniczny. Prąd wejściowy falownika dla obwodu przedstawionego jest opisany wyrażeniem

$$
\mathrm{i}_{\mathrm{f}}=\mathrm{i}_{\mathrm{A}} \mathrm{K}_{\mathrm{A}}+\mathrm{i}_{\mathrm{B}} \mathrm{K}_{\mathrm{B}}+\mathrm{i}_{\mathrm{C}} \mathrm{K}_{\mathrm{C}}
$$

\subsection{Gałąź hamowania}

Gałąź hamowania lokomotywy składa się przerywacza $\left(T_{h}\right)$, rezystora $R_{h}$. Sygnał $K_{H}$ sterujący pracą zaworu przekształtnika hamowania generowany jest w sterowniku hamowania i jego wartość logiczna 1 (stan przewodzenia przerywacza $T_{h}$ ), lub 0 (przerywacz wyłączony) uzależniona jest od wartości napięcia $\mathrm{u}_{\mathrm{c} 1}$ na kondensatorze $\mathrm{C}_{\mathrm{pl}}$. Gdy przerywacz jest otwarty przebieg napięcia na kondensatorze opisuje równanie różniczkowe

$$
\dot{\mathrm{u}}_{\mathrm{c} 1}(\mathrm{t})=\frac{\mathrm{i}_{\mathrm{fh}}(\mathrm{t})}{\mathrm{C}_{\mathrm{p} 1}}-\frac{\mathrm{i}_{\mathrm{st}}}{4 \mathrm{C}_{\mathrm{p} 1}}
$$

Liczba 4 wynika z założenia, ze obwód główny lokomotywy składa się z 4 równo obciążonych identycznych układów. Napięcie na kondensatorze rośnie do wartości określonej przez $u_{\mathrm{clmax}} \mathrm{i}$ gdy przekroczy wartość $u_{c 1 \max }$, następuje załączenie przerywacza $\left(T_{h}\right)$. Napięcie na kondensatorze zmniejsza swoją wartość i jego przebieg opisany jest równaniem

$$
\dot{\mathrm{u}}_{\mathrm{cl}}(\mathrm{t})=\left(\frac{\mathrm{i}_{\mathrm{fh}}(\mathrm{t})}{\mathrm{C}_{\mathrm{pl}}}-\frac{\mathrm{u}_{\mathrm{cl}}(\mathrm{t})}{\mathrm{C}_{\mathrm{pl}} \mathrm{R}_{\mathrm{h}}}-\frac{\mathrm{i}_{\mathrm{st}}}{4 \mathrm{C}_{\mathrm{p} 1}}\right)
$$

Napięcie na kondensatorze maleje $\mathrm{C}_{\mathrm{p} 1}$ i gdy osiagnie wartość $\mathrm{u}_{\mathrm{c} l \min }$ przerywacz zostaje przez układ sterowania wyłączony. Gdy przerywacz jest zamknięty $\mathrm{i}$ nie ma poboru energii przez inny pojazd $\left(i_{\mathrm{st}}=0\right)$, prąd z falownika (prąd hamowania) płynie przez rezystor $\mathrm{R}_{\mathrm{h}}$. Wynika $\mathrm{z}$ tego warunek na maksymalną wartość prądu hamowania.

$$
\mathrm{i}_{\text {fh }}(\mathrm{t})\left(\frac{\mathrm{u}_{\mathrm{clmax}}}{\mathrm{R}_{\mathrm{h}}}\right.
$$

$\mathrm{W}$ analizowanym systemie, podczas procesu hamowania z odzyskiem energii elektrycznej, napięcie $\left(u_{p 1}\right)$ na odbieraku pojazdu hamującego musi być większa od napięcia $\left(\mathrm{u}_{\mathrm{p} 2}\right)$ na odbieraku pojazdu który pobiera energię. Istotne jest również to, że napięcie $\mathrm{u}_{\mathrm{p} 1}$ musi być większe od napięcia jałowego podstacji. $\mathrm{W}$ przeciwnym przypadku mogłyby zajść warunki, które powodowałby, że na oporniku hamowania $\left(\mathrm{R}_{\mathrm{h}}\right)$ wydzielana byłaby energia z podstacji trakcyjnej. 


\subsubsection{Podstawowe parametry gałęzi hamowania}

Prąd $i_{\text {fh }}$ jest prądem odkształconym. Podstawowe parametry gałęzi hamowania można wyznaczyć dla uśrednionych wartość prądu hamownia. Wartość średniej częstotliwość pracy przerywacza $\left(\mathrm{T}_{h}\right)$. określa wyrażenie (17) [ 1 ]

$$
f_{p h}=\frac{I_{s h}\left(U_{s h}-I_{s h} R_{h}\right)}{U_{s h} H C_{p 1}}
$$

gdzie:

$\mathrm{H}=\mathrm{u}_{\mathrm{clmax}}-\mathrm{u}_{\mathrm{clmin}}, \mathrm{U}_{\mathrm{sh}}-$ wartość średnia napięcia na kondensatorze $C_{p 1}$ za okres $\frac{1}{f_{p h}}, I_{s h}$ - wartość średnia prądu hamowania za okres $\frac{1}{\mathrm{f}_{\mathrm{ph}}}$

Dla określenia związku pomiędzy częstotliwością pracy $f_{p}$ przerywacza, a wartością średnią momentu hamowania silnika wykorzystamy zależność na bilans mocy określonej wyrażeniem

$$
\mathrm{U}_{\text {sh }} \mathrm{I}_{\text {sh }}+\mathrm{P}_{\mathrm{st}}=\mathrm{M}_{\text {sh }} \Omega_{\mathrm{m}}
$$

gdzie:

$\mathrm{P}_{\mathrm{st}}-$ moc strat $\mathrm{w}$ obwodzie silnik, falownik, przerywacz hamownia,

$\mathrm{M}_{\text {śh }}$ - wartość średnia elektromagnetycznego moment hamowania silnika za okres $1 / f_{p}$

Przez $\mathrm{P}_{0}$ określmy wartość mocy wydzielonej na rezystorze hamującym $\mathrm{w}$ trakcie cyklu hamowania.

$$
\mathrm{P}_{0}=\frac{\mathrm{U}_{\mathrm{sh}}^{2}}{\mathrm{R}_{\mathrm{h}}}
$$

Podstawiając wyrażenie (6) do (7) i uwzględniając (8) otrzymujemy zależność częstotliwości pracy przerywacza od momentu hamowania silnika.

$$
f_{p h}\left(M_{s h}\right)=a_{h} M_{s h}^{2}+b_{h} M_{s h}+c_{h}
$$

gdzie:

$$
\begin{aligned}
& \alpha_{\mathrm{h}}=\frac{1}{\mathrm{U}_{\mathrm{sh}} \mathrm{HC}_{\mathrm{p} 1}} ; \mathrm{a}_{\mathrm{h}}=-\alpha_{\mathrm{h}} \frac{\Omega_{\mathrm{m}}^{2}}{\mathrm{P}_{0}} ; \\
& \mathrm{b}_{\mathrm{h}}=\alpha_{\mathrm{h}} \Omega_{\mathrm{m}}\left(1+2 \frac{\mathrm{P}_{\mathrm{st}}}{\mathrm{P}_{0}}\right) ; \\
& \mathrm{c}_{\mathrm{h}}=-\alpha_{\mathrm{h}} \mathrm{P}_{\mathrm{st}}\left(1+\frac{\mathrm{P}_{\mathrm{st}}}{\mathrm{P}_{0}}\right) ;
\end{aligned}
$$

Maksymalna wartość częstotliwości pracy przerywacza występuję dla $\mathrm{M}_{\mathrm{h} 02}$

$$
\mathrm{M}_{\mathrm{h} 02}=\frac{2 \mathrm{P}_{\mathrm{st}}+\mathrm{P}_{0}}{2 \Omega_{\mathrm{m}}}
$$

Maksymalna wartość częstotliwości pracy przerywacza może być również określona przez parametry gałęzi hamowania $\left(\mathrm{H}, \mathrm{C}_{\mathrm{pl}}\right)$ oraz średnią wartość napięcia na kondensatorze $\mathrm{C}_{\mathrm{p} 1}$.

$$
f_{p h}\left(M_{h 02}\right)=f_{p h \max }=\frac{U_{\text {sh }}}{4 H C_{p 1} R_{h}}
$$

\subsection{Model silnika asynchronicznego}

Silnik napędowy pojazdu trakcyjnego zasilany jest napięciem odkształconym z falownika. Do opisu dynamiki maszyn indukcyjnych zasilanych napięciem odkształconym zastosowano opis silnika asynchronicznego $\mathrm{w}$ nieruchomym układzie współrzędnych $(\alpha, \beta)$, związanych ze stojanem. Elementy macierzy stanu są zależne od aktualnej wartości prędkości kątowej mechanicznej wirowania wału silnika $\Omega_{\mathrm{m}}$. Równania te będą miały następującą postać:

$$
\dot{\mathbf{X}}_{\mathrm{e}}=\mathbf{A}_{\mathrm{e}}\left(\Omega_{\mathrm{m}}\right) \mathbf{X}_{\mathrm{e}}+\mathbf{B}_{\mathrm{e}} \mathbf{U}_{\mathrm{e}}
$$

gdzie:

- macierz stanu $\mathbf{A}_{\mathrm{e}}\left(\Omega_{\mathrm{m}}\right)$

$$
\mathbf{A}_{\mathrm{e}}=\left[\begin{array}{cccc}
0 & 0 & -\mathrm{R}_{\mathrm{s}} & 0 \\
0 & 0 & 0 & -\mathrm{R}_{\mathrm{s}} \\
\mathrm{Z}_{2} & \mathrm{Z}_{3} & -\frac{\mathrm{Z}_{1}}{\sigma_{1}} & -\mathrm{p}_{\mathrm{b}} \Omega_{\mathrm{m}} \\
-\mathrm{Z}_{3} & \mathrm{Z}_{2} & -\mathrm{p}_{\mathrm{b}} \Omega_{\mathrm{m}} & -\frac{\mathrm{Z}_{1}}{\sigma_{1}}
\end{array}\right]
$$

gdzie:

$$
\begin{gathered}
\sigma_{1}=1-\frac{\mathrm{L}_{\mathrm{m}}^{2}}{\mathrm{~L}_{\mathrm{r}} \mathrm{L}_{\mathrm{s}}} ; \mathrm{Z}_{1}=\left(\frac{\mathrm{R}_{\mathrm{s}}}{\mathrm{L}_{\mathrm{s}}}+\frac{\mathrm{R}_{\mathrm{r}}}{\mathrm{L}_{\mathrm{r}}}\right) \\
\mathrm{Z}_{2}=\frac{\mathrm{R}_{\mathrm{r}}}{\sigma_{1} \mathrm{~L}_{\mathrm{r}} \mathrm{L}_{\mathrm{s}}} ; \mathrm{Z}_{3}=\frac{\mathrm{p}_{\mathrm{b}} \Omega_{\mathrm{m}}}{\sigma_{1} \mathrm{~L}_{\mathrm{s}}} \\
\text {-wektor stanu } \quad \mathbf{X}_{\mathrm{e}} \\
\mathbf{X}_{\mathrm{e}}=\left[\begin{array}{llll}
\Psi_{\mathrm{s} \alpha} & \Psi_{\mathrm{s} \beta} & \mathrm{i}_{\mathrm{s} \alpha} & \mathrm{i}_{\mathrm{s} \beta}
\end{array}\right]^{\mathrm{T}}
\end{gathered}
$$


- macierz sterowania $\mathbf{B}_{\mathrm{e}}$

$$
\mathrm{B}_{\mathrm{e}}=\left[\begin{array}{cc}
1 & 0 \\
0 & 1 \\
\frac{1}{\sigma_{1} \mathrm{~L}_{\mathrm{s}}} & 0 \\
0 & \frac{1}{\sigma_{1} \mathrm{~L}_{\mathrm{s}}}
\end{array}\right]
$$

- wektor sterowania $\mathbf{U}_{\mathrm{e}}$

$$
\mathbf{U}_{\mathrm{e}}=\left[\begin{array}{ll}
\mathrm{u}_{\mathrm{s} \alpha} & \mathrm{u}_{\mathrm{s} \beta}
\end{array}\right]^{\mathrm{T}}
$$

Wektor sterowania silnika $U_{e}$ uzależniony jest od napięcia obwodu zasilania falownika $\mathrm{u}_{\mathrm{cl}}$ i od sygnałów sterujących $\mathrm{K}_{(\mathrm{A}, \mathrm{B}, \mathrm{C})}$.

$$
\mathbf{U}_{\mathrm{e}}=\mathbf{T}_{\mathrm{u}} \mathrm{u}_{\mathrm{cl}}\left[\begin{array}{l}
\mathrm{K}_{\mathrm{A}} \\
\mathrm{K}_{\mathrm{B}} \\
\mathrm{K}_{\mathrm{C}}
\end{array}\right]
$$

Macierz $\mathbf{T}_{u}$ opisuje relacje miedzy napięciami wyjściowymi falownika a składowymi napięciami w wektorze zasilania silnika.

$$
\mathbf{T}_{\mathrm{u}}=\left[\begin{array}{ccc}
\frac{2}{3} & -\frac{1}{3} & -\frac{1}{3} \\
0 & \frac{1}{\sqrt{3}} & -\frac{1}{\sqrt{3}}
\end{array}\right]
$$

Prądy fazowe silnika obliczamy na podstawie wyrażenia:

$$
\left[\begin{array}{l}
\mathrm{i}_{\mathrm{A}} \\
\mathrm{i}_{\mathrm{B}} \\
\mathrm{i}_{\mathrm{C}}
\end{array}\right]=\mathrm{T}_{\mathrm{p}}\left[\begin{array}{l}
\mathrm{i}_{\mathrm{s} \alpha} \\
\mathrm{i}_{\mathrm{s} \beta}
\end{array}\right]
$$

gdzie:

$$
\mathbf{T}_{\mathrm{p}}=\left[\begin{array}{cc}
1 & 0 \\
-\frac{1}{2} & \frac{\sqrt{3}}{2} \\
-\frac{1}{2} & -\frac{\sqrt{3}}{2}
\end{array}\right]
$$

Macierz $\mathbf{T}_{p}$ opisuje relacje miedzy prądami wyjściowymi falownika a składowymi prądu w wektorze stanu silnika, gdy spełniony jest warunek.

$\mathrm{i}_{\mathrm{A}}+\mathrm{i}_{\mathrm{B}}+\mathrm{i}_{\mathrm{C}}=0$ Moment elektromagnetyczny silnika asynchronicznego określono wyrażeniem

$$
\mathrm{M}_{\mathrm{e}}=\frac{\mathrm{p}_{\mathrm{b}} \mathrm{m}_{\mathrm{s}}}{2}\left(\Psi_{\mathrm{s} \alpha} \mathrm{i}_{\mathrm{s} \beta}-\Psi_{\mathrm{s} \beta} \mathrm{i}_{\mathrm{s} \alpha}\right)
$$

Podstawowe parametry silnika: $\mathrm{L}_{\mathrm{s}}, \mathrm{L}_{\mathrm{r}}, \mathrm{L}_{\mathrm{m}}$ - oznaczają, indukcyjności stojana, wirnika (sprowadzoną do uzwojenia stojana) i indukcyjność wzajemną uzwojeń, $R_{s}, R_{r}$ - oznaczają odpowiednio rezystancje obwodu stojana i wirnika (sprowadzoną do uzwojenia stojana), $m_{s}$ - liczba faz silnika, $p_{b}$ - jest liczbą par biegunów silnika, $\Omega_{\mathrm{m}}$ - prędkością kątową mechaniczna wirnika.

\subsection{Model sieci i pojazdu pobierającego energię.}

Równia różniczkowe opisujące przebieg prądu w sieci trakcyjnej oraz przebieg napięcia na kondensatorze $\mathrm{C}_{\mathrm{p} 2}$ (pojazd pobierający energię mają następującą postać:

$$
\begin{aligned}
& \dot{\mathrm{i}}_{\mathrm{st}}=-\frac{\mathrm{R}_{\mathrm{z}}}{\mathrm{L}_{\mathrm{z}}} \mathrm{i}_{\mathrm{st}}-\frac{\mathrm{u}_{\mathrm{c} 2}}{\mathrm{~L}_{\mathrm{z}}}+\frac{\mathrm{u}_{\mathrm{c} 1}}{\mathrm{~L}_{\mathrm{zt}}} \\
& \dot{\mathrm{u}}_{\mathrm{c} 2}=-\frac{\mathrm{u}_{\mathrm{c} 2}}{\mathrm{C}_{\mathrm{p} 2} \mathrm{R}_{\mathrm{p} 2}}+\frac{\mathrm{i}_{\mathrm{st}}}{\mathrm{C}_{\mathrm{p} 2}}
\end{aligned}
$$

gdzie:

$$
\begin{aligned}
& \mathrm{L}_{\mathrm{z}}=\mathrm{L}_{\mathrm{st}}(1)+\frac{\mathrm{L}_{\mathrm{dp} 1}+\mathrm{L}_{\mathrm{dp} 2}}{4} ; \\
& \mathrm{R}_{\mathrm{z}}=\mathrm{R}_{\mathrm{st}}(1)+\frac{\mathrm{R}_{\mathrm{dp} 1}+\mathrm{R}_{\mathrm{dp} 2}}{4}
\end{aligned}
$$

\section{Wnioski}

Opracowany model umożliwia oszacowanie wpływu parametrów sytemu i sterownia przerywaczem hamownia na harmoniczne prądu w sieci trakcyjnej. Na rys. 2 przedstawiono przebieg prądu w sieci trakcyjnej.
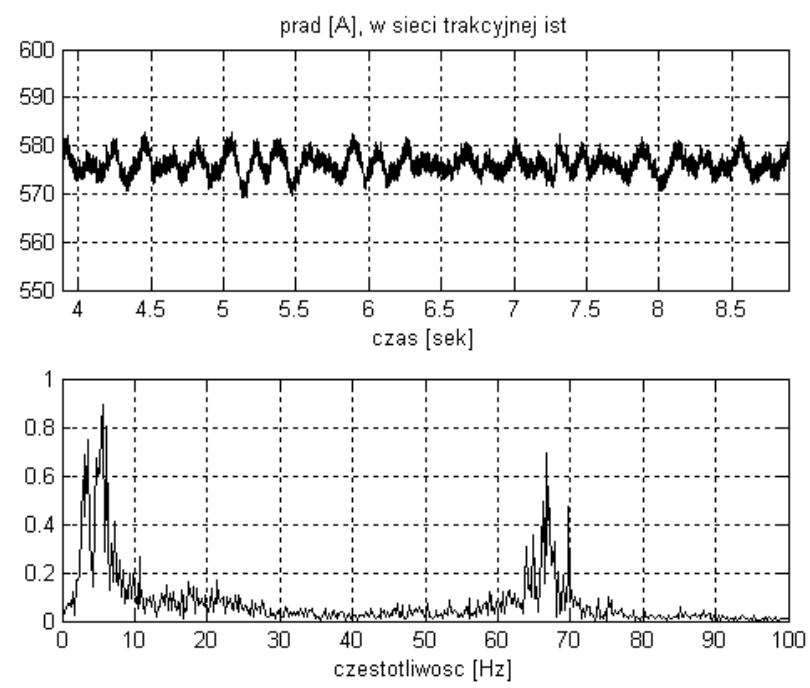

Rys. 2 a) Przebieg prądu w sieci trakcyjnej w przypadku gdy moc pojazdu hamującego jest większa od mocy pojazdu pobierającego energię, b) widmo harmonicznych prądu w sieci trakcyjnej

Dokonując zmian poszczególnych parametrów sytemu np. mocy z jaką hamuje pojazd, mocy pobieranej przez pojazd na trasie, filtru LC pojazdów, histerezy zmian napięcia na wejściu falownika, wartości rezystancji w gałęzi hamowania możemy 
analizować ich wpływ na wartość harmonicznych prądu sieci trakcyjnej. Zmiany napięcia na wejściu falownika $\left(\mathrm{u}_{\mathrm{cp} 1}\right)$ wywołane na skutek pracy przerywacza hamowania wpływają na jakość napięcia zasilania silnika asynchronicznego. Przekłada to się na dodatkowe odkształcenia prądu i momentu silnika asynchronicznego $[1,3]$.

\section{Literatura}

[1] Lewandowski M.: Wplyw pulsacji napięcia obwodu pośredniczacego na napięcie wyjśsiowe falownika. Materiaty Konferencyjne. VI Konferencja Naukowa Trakcji Elektrycznej. Semtrak 94. Politechnika Krakowska, Zakopane, 1994.

[2] Lewandowski M.: Analiza pracy uktadu hamowania lokomotywy z silnikiem asynchronicznym. X Konferencja Naukowa Trakcji Elektrycznej i II szkoła Kompatybilności Elektromagnetycznej w Transporcie. Semtrak 2002, Zakopane, 2002.

[3] Skarpetowski G., Zajac W.: Symulacja odcinka linii kolejowej o złożonym obciqżeniu konwencjonalnoprzeksztattnikowym. $8^{\text {th }}$ Int. Conf. Modern Electric Traction in Integrated XXI ${ }^{\text {st }}$ Century Europe. Warsaw 2007. 